\title{
WHERE WE ARE
}

\section{Wireless Meets the Broadband Internet}

\section{WHERE WE ARE}

Today many persons equate the word "wireless" with cellular, forgetting the huge swath of other applications this ethereal technology provides, but responding to the overwhelming success of cellular, which has grown from trial systems in the early 1980s to about 3 billion subscribers globally by the end of 2007. Market researchers are now predicting that the migration from narrowband $2 \mathrm{G}$ cellular to $3 \mathrm{G}$ wideband voice and data systems and subsequently to $4 \mathrm{G}$ networks capable of delivering true broadband mobile services to wireless subscribers will easily exceed 1 billion by 2012 [1].

As widespread interest in personal computing swelled in the early 1980 s, it became apparent that complex digital wireless technologies were able to become practical and cost effective as the effects of Moore's law, ${ }^{*}$ which had driven the success of distributed computing, spilled over into the wireless industry. The wireless industry has now emerged as an integral element in the broader digital universe of computing, software, application-specific integrated circuits (ASIC), digital signal processors (DSP), memory and logic processor chips, materials science, automated design and manufacturing tools, and storage. The immediate result of these developments is the increased velocity of product development,

* Posited in 1965 by Gordon Moore, the cofounder of Intel. Since the density of transistors on integrated circuits had doubled every year up to that time, Moore's Law stated that this progress would continue into the future, which has largely proven correct. In recent years, the pace of Moore's law has continued, but the doubling is now taking place about every 18 months.

Wireless Broadband. By Vern Fotheringham and Chetan Sharma

Copyright (C) 2008 the Institute of Electrical and Electronics Engineering, Inc. 
the commoditization of components and assembled hardware, and the efficiency and mass specialization capabilities of robotic assembly techniques.

The wireless industry has long been influenced by regulation, often heavyhanded but sometimes inspired, in virtually every nation worldwide. In the United States, at the time of this writing, there are new voices joining the public policy debate. These include the growing influence of Internet software-centric organizations such as Google, which is becoming visible on the public policy stage for the first time. The software content and applications industry has begun to pressure the Federal Communications Commission (FCC), both directly and through initiatives, to gather support in Congress to back the migration to open network access policies for future spectrum licensees.

So where are we on this evolutionary path to the future? In our opinion, we are "muddling through" [2] a period of transition to a more efficient, cost-effective, and flexible wireless broadband future. The forces of inertia, vested-interest protectionism, and alternative technology overload are arrayed against the financial tension between upside opportunities and downside risks at the extreme ends of the scale.

We will all ultimately arrive in a ubiquitous broadband world where we can access every type of service from virtually any location - the proverbial wireless broadband Internet future. How we manage the conflicts between and among the impacted parties will determine how soon the crystal clear vision of a broadband future arrives. Balancing the forces of change against the power of incumbency will require a thoughtful public policy dialogue that results in an efficient and least destructive path forward. We are going to get the future we deserve, but we will certainly deserve what we get, in a negative context, if we fail to approach the invention of our shared future and our position in the global technology market, without due care and awareness of all the issues, both positive and negative.

The present market development environment for next-generation network implementation has been formed by the tortured and financially traumatic events of the past eight years. The competitive telecommunications industry has come through a forge of financial restructurings of unprecedented scale, which has created a strong foundation of low cost facilities and has been complemented by the insidious march of technology development that both enhances network performance and reduces costs.

The following section describes the events that led to the collapse of the industry and the reconsolidation of the incumbent Bell operating companies into competitors that are more powerful than they were as independent ILECs.

\section{HOW WE GOT HERE: REINTEGRATION OF THE TELECOM OLIGOPOLY AND CRACKS IN THE WALLED GARDENS}

\section{The Disassembling and Reassembling of the Telecom Industry and the Collapse of Monopolies and of Competition}

The global telecommunications market is heading into a dramatic period of change that will result in a significant restructuring and realignment of the 
economics and financial underpinnings of the industry. The devolution of the monopoly telephone organizations into competitive environments has been progressing steadily over the past 25 years.

In 1982 the Modified Final Judgment (MFJ) [3], a modification to the original 1956 consent decree, between the government and AT\&T, after negotiations, was issued by federal judge Harold Greene to settle a suit between AT\&T and the Federal Trade Commission. This landmark decision resulted in the breakup of the Bell monopoly into seven regional Bell operating companies (RBOCs). The original 1956 Final Judgment had mandated that

- AT\&T be prohibited from entering the computer and information services business

- the Western Electric equipment manufacturer be mandated as a separate subsidiary

- AT\&T Long Distance and the local Bell companies be established as subsidiaries

- Bell Labs be separated as Telecommunication Research

The 1982 MFJ called for

- the divestiture of the local Bell operating telephone companies into seven RBOCs

- AT\&T's retention of its long-distance (LD) and manufacturing businesses

- The disallowance of RBOCs to manufacture or to get into the LD business

- the prohibition of AT\&T against providing local telephone service or acquiring the stock or assets of any of the RBOCs.

The divestiture agreement incorporated a "triennial review" system under which Judge Greene reviewed the evolving competitive telecommunications market and ruled on whether proposed AT\&T initiatives or entry into new or legacy market segments would be allowed. These triennial reviews continued well into the 1990s and were essentially rendered obsolete by the Telecommunications Act of 1996.

The original negotiated settlement was ultimately a trade-off between the allocation of assets between the new RBOCs and AT\&T. Ultimately, AT\&T decided to maintain its powerful position in the LD business, while swapping out the local access, cellular, and yellow pages businesses to the seven RBOCs. It is a widely held belief that the objective of divestiture was primarily to foster competition between and among the RBOCs, which were formidable and sizable local monopoly organizations. The evolution of the market environment, in large part driven by the advent and tremendous growth of the cellular and cable industries, eventually reduced the strict separation under the MFJ that had been overseen by Judge Greene and its relevance faded as market conditions evolved. 
However, many of the arbitrary legacy regulations and business line separations wound up being codified in the 1996 Telecom Act.

Emerging competitors persuaded the FCC into believing that the entrenched position of the legacy telephone companies gave them an unfair advantage in the marketplace and that without relief on pricing and access to facilities there would be no realistic chance for a healthy, competitive marketplace. The competitors successfully argued that they could not afford to replicate the telephone industry's end-to-end infrastructure. Consequently, the FCC promulgated a series of decisions that afforded the competitors access to parts of the existing wireline infrastructure at rates that were less than the standard retail rates charged by the ILECs. This culminated in congressional legislation, the 1996 Telecom Act, which enshrined and enlarged on these policies while creating a path for the RBOCs and their sisters in GTE and United Telecom to rejoin, provided they could demonstrate that their markets were on the road to being competitive.

Unfortunately, less than half a dozen years after the 1996 Act, much of the newly created CLEC telephone sector largely collapsed in 2000-2001. The precipitating cause of this collapse was the massive withdrawal of capital markets' interest in funding operating losses. There were a number of reasons for the almost overnight shutdown of access by the CLECs to construction and operating funds. The somewhat irrational contagion from the dot-com meltdown was one reason. It was also true that there had been widespread irrational overbuilding of duplicate fiber-optic networks on the same routes and in the same high density metropolitan areas. Too many CLECs were funded to implement virtually identical business plans in the same markets. A successful business plan, for instance, for long-haul fiber or metropolitan fiber rings was soon copied, and all too often over the same routes or in the same metropolitan area.

There were two significant contributors to the early failures among the CLECs that were common to all of them, regardless of whether they were simply resellers: facilities-based fiber network operators and wireless network operators. We will also address the impact of the behavior of the ILECs after we describe the CLECs that failed due to these factors.

Time Constraints. One problem was the comparatively short period of time available to the CLECs that had entered the market on the premises and promises of the 1996 Telecom Act who were in business before access to the capital markets was shut down. These emergent competitive organizations had only three to five years in which to build their capital-intensive businesses and networks before the market's financial collapse. In most cases, this time was insufficient for the organizations in most cases to complete network builds, to build their customer base to critical mass, and to reach positive cash flow, particularly with the debt that they had to raise in order to build even the comparatively limited amount of infrastructure their business cases required. In sharp contrast, their competitors, the legacy telephone companies, had almost 100 years to leisurely build their networks without any threat from competitive pricing. Indeed ILECs were treated as public utilities entitled to a guaranteed profit on whatever capital they invested 
in the business. In short, the more money they spent, the more they earned. Thus, they were completely protected from any bad business decisions or poorly conceived investments. The ILECs could invariably tap the equity and debt markets at almost any moment for whatever funds they needed at low interest rates. The CLECs too raised money in the equity and debt markets much as the ILECs did. However, they were usually forced to pay much higher interest rates. For instance, MCI Telecom, which was the first CLEC, was one of the first companies to raise debt through high yield debt securities, the so-called junk bonds pioneered by Michael Milken at Drexel Burnham. The rates on these bonds were two to three times the rates paid by the legacy telephone companies. When the downturn came, the CLECs were the hardest hit. When their stock prices plummeted, they fell into default on the covenants for the high yield debt securities burdening their balance sheets. In most instances, they also had too small a customer base to pay the interest rates and were unable to raise additional equity.

The Virtuous Circle Turned Vicious. The venture capital (VC) and private equity industries, fully aided and abetted by the investment banking industry, were responsible for the early funding of the CLEC industry and hence for their existence. However, their participation all too often came at a price, which contained the seeds of failure. In their frenzy to exact fees from the process and attract investors, the investment banks usually insisted on unrealistic business plans.

In the late 1980s, the common time frame in which a VC sought a return on its investment was five to seven years. By the mid 1990s, this period was drastically truncated to 18-36 months. This meant that a new CLEC was expected to "go public" or be acquired in less than three years from its initial funding. In order to be attractive to the public markets and to third-party acquirers, the CLECs were urged to build rapidly and expansively. For instance, in the case of the three fixed wireless companies that went public in this period (Teligent, WinStar, and Advanced Radio Telecom) and each of which ended up bankrupt, all were pressured to rapidly rollout nationwide deployments. The mantra of the investment banks was, "We only back category leaders and to be a category leader in this industry you have to be national." For an early stage company, no matter how experienced the founders and line management, this was a monumental undertaking not only in terms of capital but in terms of human resources and management systems. At least in retrospect, this approach was doomed to failure, and fail it did devastating the equity values of numerous companies that had invested tens of billions in state-of-the-art new network infrastructure.

Virtually all of the sector leaders went public early with ambitious plans to expand rapidly nationwide, tapping the high yield debt markets to fund their growth, and subsequently had to seek bankruptcy protection and restructuring. This trend resulted in an extraordinary reduction in their equity values, as they were reorganized with the debt holders emerging as the new equity base. Thus, with the bondholders becoming the new equity owners, the resulting restructurings led to a dramatic slowdown in CLEC expansion and operations, which subsequently 
trickled down to the broader telecommunications support industry, damaging numerous equipment vendors and many professional services organizations that had emerged to support the rapid growth.

A Description of Competitors Who Failed. The leading facilities-based CLECs and (data only) DLECs that were driven into receivership included the following:

1. XO Communications

The largest surviving CLEC, XO Communications went bankrupt and was reorganized under XO Holdings (listed under OTCBB: XOHO); Carl Ichan now controls it. XO also owns Nextlink Wireless, its subsidiary for wireless broadband access services, which holds the largest footprint of $28 \mathrm{GHz}$ LMDS (Local Multipoint Distribution Services) licenses throughout the United States.

2. McLeod USA

Headquartered in Cedar Rapids, Iowa, McLeod USA is a CLEC and interexchange carrier (IXC) that provides integrated voice and data services to small and medium sized businesses in a service territory that includes the Midwest, the Rocky Mountain states, and portions of the Southwest and Northwest United States. The company provides traditional local and LD services, and high speed Internet and value-added data services.

3. Network Plus

Network Plus was acquired out of its prepackaged bankruptcy by Broadview Networks, which continues to use Network Plus to provide integrated service provider operations in the northeastern region of the United States.

4. Mpower

Mpower was acquired by TelePacific, a California CLEC, which subsequently sold Mpower of Illinois to McLeod USA in May 2007. The combined entity is now being acquired by Paetek, headquartered in Fairport, New York, to add to its existing footprint of CLEC-integrated voice, data, and Internet services.

5. e.spire

e.spire was acquired out of bankruptcy by Xspedius Communications, LLC, headquartered in O'Fallon, Missouri. Xspedius provides integrated telecommunications services to small to medium sized enterprises (SME) throughout the southern region of the United States. Xspedius was created through the consolidation of several telecommunications companies, including its original operations in Lake Charles, Baton Rouge, Lafayette, Memphis, Nashville, and Greensboro/Winston-Salem. In August 2002, Xspedius purchased substantially all of the assets of Virginia-based e.spire Communications, which added 55 markets across 20 states, and more than 3,500 total route miles of fiber to Xspedius' assets. 
In January 2003, the company acquired Mpower Communications' Texas assets in the Dallas/Fort Worth, Houston, Austin, and San Antonio markets. In April 2005, Xspedius purchased the business and assets of ICG Communications Inc. in five markets across the Southeast, enhancing its service in Atlanta, Birmingham, Louisville, Nashville, and Charlotte, NC.

6. Focal Communications

Focal was on the brink of insolvency when it was sold to Broadwing Communications, the CLEC subsidiary of Corvis Corporation, in September 2004. Subsequently, Level3 purchased Broadwing Communications in January 2007 to expand its portfolio.

7. Broadband Office

This Kleiner Perkins and real estate industry-backed venture was lavishly funded with approximately $\$ 250$ million in VC, which it consumed in only about 18 months, while seeking to capture the major office buildings as the "last monopolies" for telecommunications services. It folded in the midst of the CLEC implosion in 2000-2001.

A number of very large Internet service providers (ISPs) were also driven to seek bankruptcy protection, followed by restructuring or liquidation, including

1. PSINet

2. Ardent Communications (CAIS Internet)

3. Excite@Home

4. iBeam

5. NetRail

6. colo.com

7. Exodus

In addition, most of the leading fiber-optic network operators and competitive IXCs were swept into the massive destruction of equity among the facilitiesbased carriers. The bankruptcies in this sector included

1. 360 Networks

2. Ebone/GTS

3. Global Crossing

4. Storm Telecommunications

5. Enron Broadband

6. MCI-Worldcom

Also pushed into restructuring were all of the leading broadband wireless and several of the leading mobile data and satellite pioneers, including

1. Winstar

2. Teligent 
3. Advanced Radio Telecom

4. Formus

5. OmniSky

6. Metricom/Ricochet

7. GlobalStar

8. Iridium

A similar fate befell the competitive DSL access service providers. The competitive DSL providers sought to leverage the "unbundled" copper network elements of the ILECs, which had been made available to them by the 1996 Telecom Act.

Each of the pioneering firms in the DSL space were either forced out of business or forced to reorganize in following widespread telecom sector financial market collapse. The most noteworthy of these were

1. Covad Communications

2. NorthPoint

3. Rhythms NetConnections

In our opinion, the provisions of the 1996 Telecom Act that made the lastmile copper loops of the ILECs available for lease to the DSL providers and that permitted them to install their own digital subscriber line access multiplexers (DSLAMs) in the ILEC central offices well illustrate the law of "unintended consequences." The effect of the Act was to tie the DSL providers inexorably to the ILECs. The competitive DSL companies became utterly dependent on the ILECs' last-mile facilities. This dependence meant that they were subject to whatever pricing and conditions of service that the ILECs were permitted to impose. This in turn meant that when, as was inevitable, the ILECs gained the ability to increase prices, to dictate onerous service conditions, and even to deny them access to certain facilities, the DSL providers' business cases were torpedoed. And the ultimate irony was that the DSL providers initially were flooded with capital that otherwise could have been spent on constructing alternative last-mile facilities, which would have had twin advantages: the consumer, especially the SMEs, would have had a second set of competitive facilities to leverage and the DSL providers would have not been at the mercy of the ILECs.

In addition to these DSL access providers, there were hundreds of ISPs, who were resellers of competitive DSL services, also suffered substantial damage. One of the principal culprits, though, was not just the capital markets or the downturn in customer demand. Rather, many of these ISP resellers suffered as a result of pernicious practices of some of the ILECs. These practices at best amounted to "strategic incompetence."

It would have been manifestly illegal for ILECs of any stripe to refuse to provide access to their copper facilities to the DSL resellers. It was, however, not illegal for the ILECs to provide poor service to the resellers who were competing 
with them, but who were nevertheless dependent on them, or at least, it was much more difficult for the competing resellers to prove the existence of a sufficiently pervasive and systematic pattern of poor service to amount to an illegal practice. The opportunity for harmful activities arose from the need for the ILEC as the wholesale provider to continually take actions in cooperating and coordinating with the reseller to cut over service to customers switching from the ILEC to the reseller.

The ILEC actions included such "techniques" as being late for appointments, missing appointments, and refusing to coordinate reasonable time windows for appointments with their wholesale customers, thus forcing their competitors' customers to lose a full day of work, just to be home to meet with the twin installation crews required to obtain the basic DSL service. If an appointment were missed, the customer faced the potential of losing a second day of work in order to have his or her DSL installed. In what could not have been a coincidence, it was not unusual for a marketing representative of the ILEC to contact the competitor's prospective DSL customer after the reseller had notified the ILEC of the impending cutover. The ILEC salesperson often sought to sell the putative reseller customer the same service being offered by the reseller, often at a lower price, with a promise that it could be installed within a narrow appointment time window on the targeted installation day.

It was also common for the new service providers to invest in automated provisioning systems to streamline their customer relationship management processes. Unfortunately, for them, the ILECs almost always demanded that manually prepared facsimile order forms be sent to initiate service orders. The ILECs made this demand despite the probability that they could have easily absorbed the capital and operating net cost of accepting automated transfers. The manual processes had several defects. They were an unnecessary expense to the competitive providers in both additional capital and additional operating expenses. They also often resulted in transcription keystroke errors, which led to additional correction costs, delayed the activation of the switchover of the proposed customer, and created an image of poor quality among the competitive DSL providers.

We do not know how pervasive these practices were, or to what extent to they were actions of rogue employees resentful of the new competitors and concerned about job security, or if they were actions sanctioned or at least condoned by senior management of one or more of the ILECs. We are, however, convinced, on the basis of our own experience and many anecdotes from others, that these practices were sufficiently widespread to have had a seriously negative impact on the DSL resellers. Were these actions just coincidence, or did they represent unfair competition? It was an argument that never got resolved, because both the DSL access providers, and most of their reseller ISP customers failed to survive to wage an effective challenge. In the same period, the ILECs were openly exercising their legal prerogatives to challenge various elements of the 1996 Telecom Act and the FCC's implementations of it. For instance, the ILECs filed lawsuits to seek redress against what they claimed were constitutionally illegal "takings" of their assets under the Act. These rearguard actions extended the resolution of many critical commercial settlement matters 
between the new competitors and the ILECs. It also muddied the water for numerous new competitors seeking to finance their operations and indeed to obtain fair treatment for the ILECs on reciprocal compensation and related matters. The ILECs had an unfair advantage in the legal challenges. They had orders of magnitude larger war chests, much of which was built upon monopoly utility profits. Because they had much larger cash flows and a much larger customer base, they could easily afford the cost and uncertainty of lawsuits.

The net impact of the myriad complaints lodged by upset customers against the new competitors was immense. Every truckroll required to provision a new DSL customer cost the new competitor approximately one year's profit from a single customer. The new DSL innovators and their resellers faced substantial financial obstacles quite apart from the nonavailability of capital in attempting to implement the spirit of the Telecom Act. Ultimately, virtually all of the leading firms in the DSL sector were either merged with or sold in distress to the ILECs, ending the grand experiment of a forced facilities resale concept advocated by its authors in Congress. To this observer of the "law of unintended consequences," it has been proven beyond a doubt that the only telecommunications service providers with any substantial chance of developing into true competitors to the ILECs will be those that have access to their own autonomous infrastructure or those that can operate fully open, shared public networks solely on a wholesale basis, open to all comers on equal terms, as has been successfully implemented in the United Kingdom with the structural separation of British Telecom (BT).

\section{Reassembly of the Old Telephone Alignments}

Many of the major new telecom providers only avoided bankruptcy at the beginning of this century by merging with established companies that had sufficient cash to sustain the significant operating losses that were common among carriers of all types. The Qwest merger, in reality their absorption by the former ILEC/RBOC, US West, is a prime example of the integration of the new innovative competitors into the establishment. One interesting and valuable aspect of this trend was that the legacy players were able to upgrade and expand their facilities, often at a substantially lower cost than the actual market value of the facilities, through these acquisitions of the newcomers out of or on the brink of insolvency. As a result, the innovative state-ofthe art infrastructure installed by the new entrants in the late 1990s, and then purchased by the legacy carriers, now represents a significant portion of the highest quality telecommunications infrastructure in the United States.

Since the almost complete collapse of the leading organizations challenging their market dominance, the incumbent telephone companies have spent most of their energies on acquisitions and consolidation of their market positions rather than investing in upgrades or extensions of their facilities and customer base. In the United States, this activity has amounted to a reintegration of the traditional telephone industry.

As we have shown earlier, for almost a century before "divestiture" of the Bell System and GTE in 1984, the U.S. telecom industry was dominated by one 
vertically and horizontally integrated giant. The Bell System combined the dominant LD provider, AT\&T Long Lines, and seven RBOCs, which were each the dominant ILEC in their region, besides being the leaders in technology development (Bell Labs) and in manufacturing (Western Electric). The mergers allowed by the 1996 Telecom Act over the past decade have lead to the emergence of two massive organizations, which together dwarf the old Bell System. Verizon was created by the merger of Bell Atlantic and Nynex and then added the assets of the largest CLEC, MCI-Worldcom assets, and most recently announced the acquisition of Alltel. Southwestern Bell rolled up four of the other former seven Bell "sisters" along with AT\&T Long Lines. Southwestern Bell, renamed first as SBC and now as AT\&T, consolidated AT\&T IXC operations, Pacific Bell, Ameritech, Bell South and the AT\&T Wireless operations, and Cingular Wireless.

In at least one critical aspect, these two consolidations have a wider, potentially more pernicious, impact on the consumer than the old Bell System. At the time of divestiture, the mobile telephone industry was in its infancy. Although in the United States AT\&T pioneered the mobile industry, the early leaders were independent innovators such as Craig McCaw, who originally made his fortune in the cable industry and who now heads Clearwire, a leading firm in Mobile WiMAX implementation. Now, however, as we will show in the next section, the top two mobile providers, AT\&T and Verizon, are also the two largest landline and cellular service providers. Thus, the reintegration of the old-line telephone industry has extended its oligopoly into the mobile arena.

Worse news awaits consumers in that AT\&T and Verizon are in by far the best position to dominate the quadruple-play offerings that will become essential buys for most of them. Quadruple play refers to the provision of voice, data (primarily Internet access), television, and mobile by one carrier - the ultimate in one-stop shopping. Many years after the first promise of cross-industry competition between the cable and television industries, and some years after the industries publicly backed away from direct competition, telephone companies are now deep into the implementation of fiber-based television services to the consumer. Both AT\&T and Verizon are presently touting fiber-to-the premise (FTTP) implementations to deliver fully converged video, voice, and high speed data solutions to their customers. Verizon is further along with their deployments, claiming that about 7 million homes passed circa December 2007; yet, compared with its existing almost 48 million access lines, the subscriber uptake of only about 515,000 FiOS subscribers represents only a tiny fraction of its service footprint.

The direct competition in live video offerings between the cable and television industries, coupled with the limited competition from direct-to-the-home satellite offerings, is certainly a boon for the consumer, at least at first blush. The shortcoming stems from the fact that the cable television MSOs do not now offer mobile services. Thus, the cable MSOs cannot, at present, effectively compete against the telephone industry in quadruple-play offerings. The recent announcement of the Comcast, Time Warner, and Bright House participation in the newly merged and expanded Clearwire mobile WiMAX rollout may alter this situation dramatically. 
Prior to the Clearwire initiative, the leaders in the cable industry had developed a tentative plan to remedy this severe competitive handicap. Led by Comcast, the majority investor, and accompanied by Time Warner, Cox and Bright House Networks, the larger MSOs formed Spectrum Co. and paid $\$ 3$ billion for $30 \mathrm{MHz}$ of advanced wireless services (AWS) spectrum at 1.7 and $2.1 \mathrm{GHz}$ in FCC Auction 66. This spectrum can be used for $3 \mathrm{G}$ and $4 \mathrm{G}$ mobile services. However, the timing and methodology for rolling out mobile services using this spectrum are uncertain. The cable MSOs have been largely silent on their plans, which, in any event, appear to have suffered a setback because of the withdrawal of their only experienced wireless player. In August 2007, Sprint, which had paid \$100 million to be part of Spectrum Co., withdrew as part of the substantial reorganization and retrenchment caused by its losses in its basic cellular services. Although the newly acquired mobile spectrum should allow the cable MSOs to eventually compete in quadruple-play offerings, they will be lagging behind by a significant margin for some time to come. The cable industries' serious handicap in competing in quadruple-play offerings is exacerbated by their handicap in competing in the triple-play offerings. The cable industry leads the telephone industry by wide margins in its core business of television fare. However, the MSOs are latecomers in the other two triple-play offerings, voice and Internet access. The MSOs have strong offerings in digital voice and Voice over Internet Protocol (VoIP). Their market shares, however, remain much smaller than the ILECs, and as they endure the inevitable growing pains to design, implement, and shake down their installation, maintenance and repair teams, they too face the conundrum that so afflicted the CLEC industry: how to build a nationwide customer care system and resources from scratch to compete against one that was built and continually exercised over decades. Meanwhile, the ILECs have not been idle. They have been constantly improving their Internet DSL service, extending the range they are able to serve customers from the central offices by improving signal quality and bandwidth. The ILECs continue to lead the cable industry in Internet market share and, by a wide margin, in voice market share.

In sum, from one perspective, consumers are right back where they were in the early 1980s - faced with a reintegrated telephone industry. On the other hand, they have options that did not exist then-competitive triple-play options from the cable industry in a growing number of communities and the prospect of a quadruple-play option from the cable MSOs. Furthermore, the ILECs have behaved as they used to when they were a monopoly. Given the collapse of the equity base of the competitors among the CLEC and ISP communities, it seems logical that the ILECs would have invested most of their capital in their own infrastructure. They might have been able to secure a "game over" unassailable position of market dominance. Unfortunately for their shareholders, but fortunately for the consumer, the ILECs' focus on mergers and acquisitions of legacy infrastructures and a legacy customer base largely consisting of traditional telephone service customers has left them exposed to the efforts of their more innovative competitors in triple-play services. Despite the ILECs' best efforts at improving their DSL service, cable MSOs are offering a superior service. Once these cable MSOs raise their digital voice and Internet customer service to ILEC standards, they will inevitably trump 
the ILECs' DSL services. However, had the ILECs invested widely in the deployment of FTTP earlier, they could have achieved the virtually unassailable position of market dominance. Their failure to have implemented earlier either widespread fiber or DSL network upgrades has left them exposed to the risk of a substantial diminution in their market position, should their emergent broadband IP-based competition in the fiber, coax, and wireless domains execute their comprehensive deployment plans in a timely manner.

\section{The Wireless Incarnation of the Telephone Companies and Their Continued Attempts at Defending Their Market Power: "Walled Gardens"}

As noted earlier, at the same time as the ILECs were reconsolidating into institutions of almost unprecedented scale, they have also been rolling up the cellular telephone industry at a rapid clip. AT\&T and Verizon are now the largest and second-largest cellular operators, respectively. Their combined share of the wireless industry is approximately 53\% (Fig. 1.1).

The market power that their size in the mobile industry affords AT\&T and Verizon has been reinforced and perpetuated by the practice of creating what are commonly termed "walled gardens." This practice is not the province only of ILECs. It has been a common practice among all mobile service providers since the genesis of the mobile industry almost three decades ago. It perpetuates the market power of the large mobile providers, while simultaneously crippling

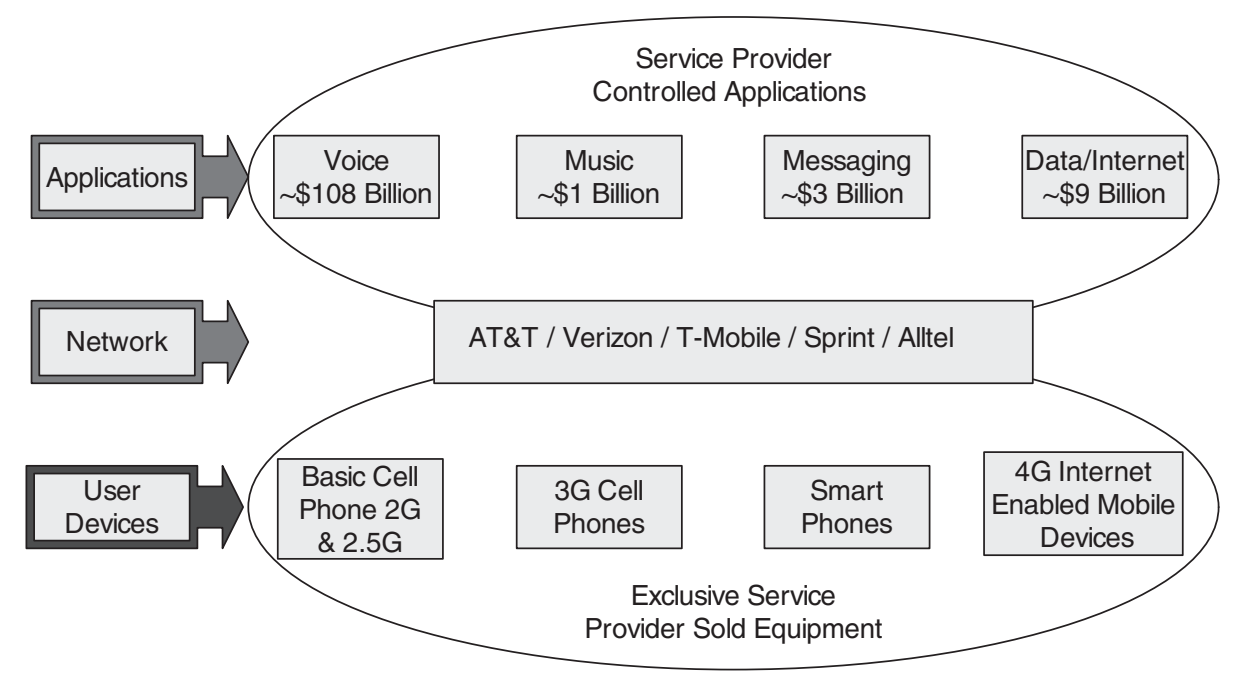

Figure 1.1. Cellular oligopoly in the United States-the "walled garden" model. Competition among the cellular operators has been limited to the horizontal plan. 
innovation and competition among the vertical markets that support the cellular operators for subscriber equipment, content, and applications.

The rubric "walled gardens" refers to the practice, familiar to all consumers, whereby the mobile provider erects a barrier against the consumer using a mobile handset other than what the mobile carrier blesses. This prohibition is reinforced and extended by the common practice of selling the handsets at rates that are substantially below standard retail prices. The quid pro quo for the carrier is a long-term contract with substantial penalties for early termination. The consumer is thus locked into a particular carrier that provides a limited range of equipment for an extended period of time. It becomes very difficult for a new service provider or reseller to compete. The market becomes, as it has in this instance, much more concentrated than it would have been otherwise. The consumer suffers in multiple ways, as he or she always does when competition is stifled-less price competition and fewer innovations in service features and pricing plans.

This type of tight control over subscriber equipment and discrimination against applications and equipment not sourced through the mobile carriers are in direct opposition to the long-standing policies that were imposed on the legacy wireline telephone companies in the Carterfone decision of 1969.* The consumer and the industry would be better served if the cellular industry were to adopt a universal attachment equivalent to the ubiquitous RJ-11 at the terminal edge of the wired telephone network.

The equivalent opportunity in the wireless industry is the common air interface that has always existed under the various cellular standards, but that has been consistently blocked by carriers to limit access to phones sourced only through the carriers' own distribution channels or resellers. There is, however, late breaking news in this regard from the second-largest U.S. mobile carrier, Verizon. The final portion of the next section will address the very encouraging announcement regarding its pledge to open its network to any compatible user equipment by November 2008. On March 18, 2008. Verizon released its initial policies regarding just how "open" it was going to become. It will remain the gatekeeper for certification of all devices to be enabled on its new "open network." Thus, it will take the market a while to determine just how unfettered Verizon actually intends to operate with third parties selling devices directly to consumers for use over its network, and how applications developers will be able to deliver its services openly to individual users without cutting Verizon into the revenue potential beyond their income for providing IP access and transport.

\section{The Pending Deployment of Mobile WiMAX Overlay Networks}

The other players in the cellular industry, which lag behind the former members of the Bell System in size, have also been expanding through sequential acquisitions of operating companies and spectrum assets. Sprint Nextel, T-Mobile, and Alltel have emerged as the primary alternative players in this space. Sprint's combination

* The landmark Carterfone decision by the FCC, June 26, 1968. 
with Nextel uniquely positions it to pioneer next-generation broadband wireless mobile services using the spectrum that it now commands post the acquisition of the MCI-Worldcom MMDS (now BRS-Broadband Radio Service) spectrum holdings and the spectrum resources that were in Nextel's possession prior to the merger. The Mobile WiMAX division of Sprint Nextel has been named XOHM. Clearwire, Craig McCaw's entry into the Mobile WiMAX market, is another major spectrum holder with the resources to potentially challenge the legacy cellular operations of the ILECs.

On July 19, 2007, XOHM and Clearwire announced, with much fanfare, the creation of a partnership for the mutual development of a nationwide Mobile WiMAX network. They proposed to divide their markets, with each concentrating on a particular region with common branding, roaming agreements, and a number of other efficient sharing arrangements. The promise was the first, and quite substantial, build out of next-generation fixed and mobile wireless facilities using the WiMAX protocols by a combination of resources fully capable of challenging ILECs' mobile supremacy.

Curiously, less than four months after announcing their intention to jointly pursue the nationwide deployment of Mobile WiMAX services, XOHM and Clearwire announced that they were unwinding their combined efforts. The change in leadership at Sprint, with its board of directors replacing Gary Foresee with Dan Hesse as its CEO, and continued challenges to the consolidation of the Nextel iDEN ${ }^{\mathrm{TM}}$ (Integrated Digital Enhanced Network from Motorola)-based network with Sprint's core mobile PCS business based on code division multiple access (CDMA) technology, apparently led to the inability of the two parties to reach a mutually acceptable agreement. Because of the long history and close association between Mr. Hesse and the Seattle wireless community, these discussions were reignited, and the subsequent merger of Sprint Xohm and Clearwire was finally announced on May 7, 2008. This new combined organization will also be sponsored by a consortium consisting of Intel, Google, Comcast, Time Warner Cable, Bright House networks, and John Stanton's Trilogy Equity Partners. At the time of this writing the merger is in the approval process by the FCC and the Justice Department with a closing expected during the fourth quarter of 2008 .

Breaches in the Walled Gardens. To what extent will the new and expanded Clearwire affect the deployment of comprehensive Mobile WiMAX overlay networks? Suffice it to say, at the time of this writing, that question looms large and significant, with no answer yet. However, there was a positive aspect to the $\mathrm{XOHM} /$ Clearwire merger that might have favorably influenced similar developments for Mobile WiMAX networks by other potential competitors. The Clearwire carrier combination has pledged to deliver services over an open network interface that would allow customer-owned devices to have unfettered access to the Internet, i.e., a consumer could connect any device that he or she wished to a Clearwire-provided mobile network connection, regardless of whether it was furnished or approved by Clearwire. This is the first of the anticipated wireless broadband extensions of the global Internet to any location using small mobile devices. 

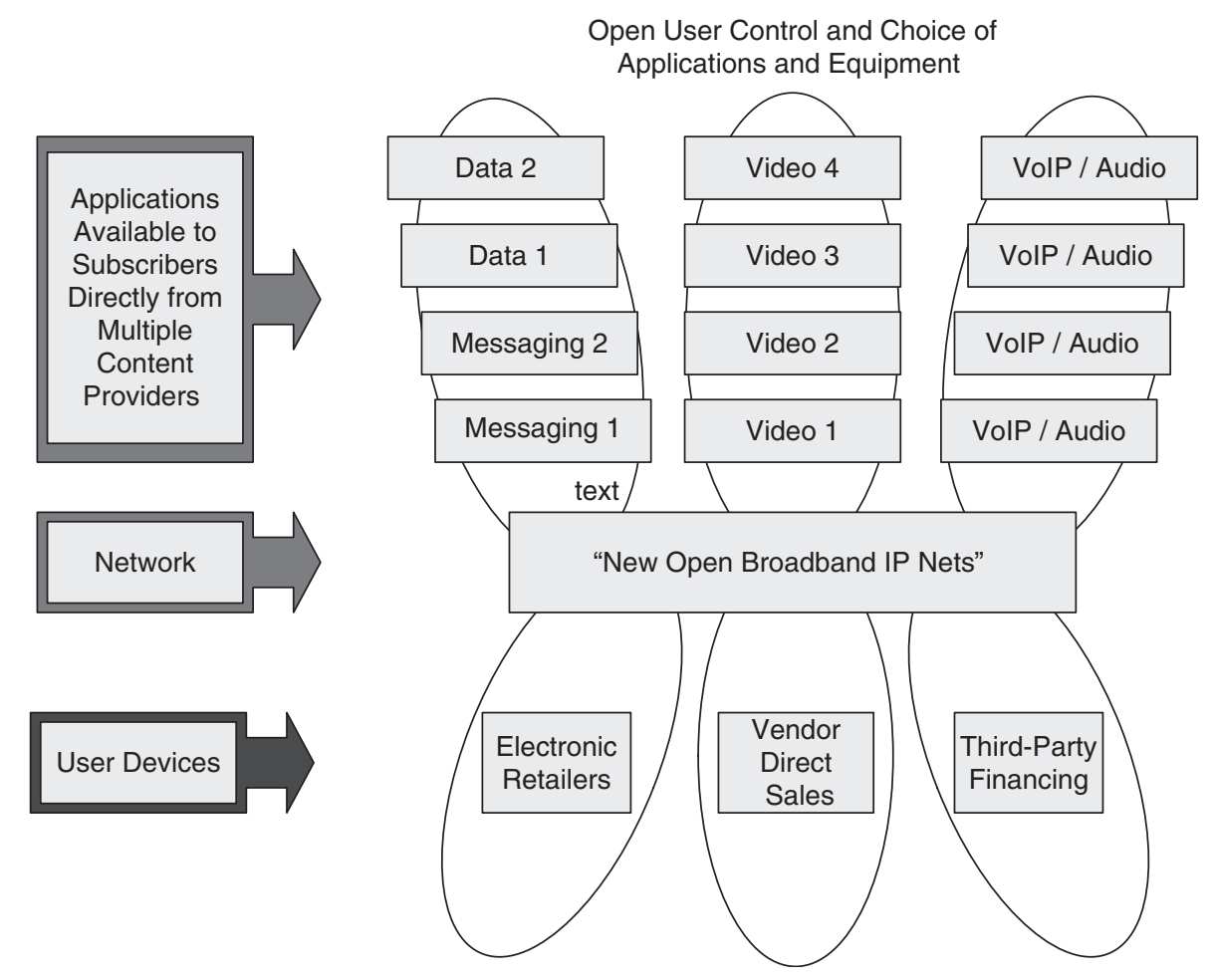

Figure 1.2. Open cellular services model—the "unwalled garden."

The Clearwire concession to open access was but the first breach in the previously sacrosanct walled garden business model that the mobile providers had been able to impose for more than two decades. Their proposal was followed soon after by Google's open and notorious open access lobbying in connection with the $700-\mathrm{MHz}$ spectrum auction, which was seconded by other participants. The FCC responded favorably to this "open network" proposal by incorporating a requirement for the $700-\mathrm{MHz}$ auction to mandate open access if a minimum bid of $\$ 4.6$ billion was obtained for the $\mathrm{C}$ Block spectrum. The hurdle was met, and both Verizon and AT\&T dominated the bidding, with Google not purchasing any spectrum in the auction, but providing Google with a huge win based on regulatory lobbying, and retaining its neutral stance as a software, content, and advertising entity among all service providers. This section concludes with the fairly safe prediction that the era of the walled garden is coming to a well-deserved end, to the great benefit of the consumer and of market competition.

The next generation of the wireless broadband-enabled world will be filled with adaptability and user-controlled preferences and choices among content providers of all types, from basic voice to video interactivity (Fig. 1.2). 


\section{0-MHz Auction Participants and Results}

At the time of this writing, the FCC has completed the $700-\mathrm{MHz}$ auction. The public-private D Block spectrum did not receive sufficient bids to clear the reserve price. The FCC and Congress will reevaluate this failure to thrive and decide how to bring this unique public-private initiative into reality. The following is a brief discussion of the issues and proponents of these new business models.

Cyren Call. One of the most noteworthy recent FCC regulatory developments was the creation of a mandated public-private partnership. Under this approach, the winner of the $\mathrm{D}$ Block portion of the $700-\mathrm{MHz}$ auction would have had an additional $10 \mathrm{MHz}$ of spectrum added to its own in exchange for voluntarily constructing a nationwide public safety wireless broadband network that leverages the commercial network's infrastructure, backbone, and applications. Morgan O'Brian, one of the original founders of Nextlink, has promoted this concept. The FCC adopted rules to authorize this scheme in July 2007. The D Block commercial licensee would gain access to use the spectrum licensed to the Public Safety spectrum to provide nonpriority wireless broadband services to commercial subscribers, while simultaneously meeting Public Safety's critical communications needs in key areas such as network coverage, availability, and reliability and ensuring that Public Safety users will automatically receive first priority access rights on the network.

On October 5, 2007, the Public Safety Spectrum Trust Corporation (PSST) announced the appointment of Cyren Call Communications Corporation as its advisor. This confirms Cyren Call as the primary liaison between the PSST and the commercial sector, including all parties interested in bidding for the upper $700-\mathrm{MHz}$ D Block license that will seek to partner with Public Safety in the creation of the nationwide, shared use wireless broadband network.

Frontline Wireless. Frontline Wireless was organized by a team of telecommunications industry veterans with deep roots in the government and in industry. It had expected to be a major bidder in pursuit of the $700-\mathrm{MHz}$ D Block spectrums. It had assembled a team of luminary participants, sponsors, investors, advisors, and lobbyists to support its initiative. Unfortunately, the organization announced its nonparticipation in the auction at the deadline for making the bidding credit deposits.

As originally stated on the Frontline Wireless website, "Frontline Wireless envisions a $4 \mathrm{G}$ wireless broadband network that will make advanced Internet services as ubiquitous as the air we breathe. By leveraging efficiencies of shared spectrum and network infrastructure, Frontline will empower first responders with state-of-the-art technology and liberate consumers from the 'walled gardens' of the incumbent wireless providers."

In addition to meeting public safety agencies' needs for fully interoperable broadband communications networks, Frontline had also promised to provide fully open access services to commercial service providers and the general public.

Had Frontline been able to deliver on its promises, it would have created a formidable counter to the legacy cellular operators, with the implementation of a 
true nationwide $4 \mathrm{G}$ network well in advance of the technical evolution Cellcos hoped for. There have recently been calls for investigation into the reasons for the collapse of Frontline and the events that led to its sudden demise.

\section{FLEXIBILITY COMES TO WIRELESS SPECTRUM}

\section{The Demise of Regulatory-Designed Single-Purpose Spectrum}

Almost since the advent of radio, different wireless services have been provided over discrete networks and discrete portions of the radio spectrum. We obtained our radio services over separate slices of AM and FM radio spectrums. Our television was broadcast to receivers using separate portions of the VHF and UHF spectrum. Our cellular phones were brought to market using the $800-\mathrm{MHz}$ spectrum and $1800-\mathrm{MHz}$ spectrum bands, which were allocated by the FCC for the provision of what were initially just voice communications. Virtually all of the radio spectrum was sliced and diced into small portions, which were designated by service rules for specific applications and services.

The lengthy process by which the FCC, circumscribed by International Telecommunications Rules, adopted these narrowly defined service rules limited innovation and forestalled the introduction of new services. The incumbents in a particular service used the rule-making process to devastating effectiveness in protecting their domains and investments. Often, by the time the service rulemaking procedure had been completed, technological advances, for instance, in dynamic bandwidth reallocation and merging of fixed and mobile uses, rendered the rigid rules obsolete. Michael Powell, former chairman of the FCC, stated the issues succinctly at his press conference on "Digital Broadband Migration" on October 23, 2001. Regarding spectrum allocation policies, he stated,

Put simply, our Nation's approach to spectrum allocation is seriously fractured. There have been dramatic changes in spectrum requirements and technology and services that use spectrum since 1934. Yet, while we have made some major strides in how we assign spectrum (principally through auctions), allocation policy is not keeping pace with the relentless spectrum demands. The spectrum allocation system is not effectively moving spectrum to its highest and best use in a timely manner.

The central problem with our current approach is that it is a command and control approach that requires government officials to determine the best use for spectrum and to constantly change the allocation table to accommodate new spectrum needs and new services. This is becoming an impossible task in today's dynamic environment.

The consequence of our current system is that it is entirely reactive. With new emerging uses, the Commission must not only evaluate and react to the new services, it must also deal with the conflicting set of legacy allocation decisions. New services are forced to demonstrate demand for the service to 
justify modification of the allocation table. Lack of proof, however, makes it hard to do so and unleashes a highly politicized process. Existing users move to block new uses and line up support for their position, and the new providers are forced to do the same. The ultimate decision is reached as a result of a politicized reactive process.

Additionally, spectrum allocation policy provides few incentives for using spectrum efficiently. Existing holders have little incentive to consider using their spectrum for more valuable uses, since allocation restrictions will prevent consideration of alternative uses. Moreover, once a carrier obtains spectrum it has little incentive to use it efficiently where there is no flexibility.

Any policy change must respect that spectrum is a public resource and must be employed for the benefit of consumers.

Over the past decade, the FCC has been slowly but inexorably relaxing its restrictions. More and more frequently, the FCC is allowing the licensee, particularly in the commercial transport services addressed here, to provide any type of service it wishes, subject only to its noninterference with other uses within or adjacent to the band.

The advent of the wireless mobile broadband Internet will accelerate the trend to abandon these traditional, narrowly defined approaches to spectrum management and radio services. Generic wireless broadband IP networks will not require spectrum partitioning and isolation. Instead, multiple applications and services will share network resources. Network operators will isolate their discrete information through the creation of virtual private networks and security measures to maintain privacy and the security of the data streams. Discrete vertical market applications will be driven by software, not by dedicated narrowband spectrum allocations and restrictive service rules.

\section{THE WIRELESS TECHNOLOGY DIASPORA}

There has been an almost complete shift of telecommunications equipment manufacturing to developing nations and third world countries. The major infrastructure and user terminal manufacturers have evolved their business models to leverage the outsourcing of the manufacturing process. Silicon Valley vendors have become essentially "virtual manufacturers," benefiting via cost reductions through outsourcing many development and manufacturing tasks (no permanent labor force) and in being able to shift product lines quickly to adapt to rapidly changing market requirements.

As the capability to develop and manufacture complex wireless infrastructure hardware has extended to the developing world, industrial development policies have emerged to provide both financial incentives to carriers and various protections to domestic national interests and franchises. Early examples of this trend were evidenced in Japan, which used its domestic regulatory process to localize technology standards and products that were primarily developed and 
supplied by its local vendors. Korea followed the Japanese model for industrial development, and most recently, we have seen China pursuing a similar course to ensure that a significant portion of its telecommunications infrastructure is sourced from its domestic industry. This local specialization has often led to the creation of local subsidiaries by multi-national manufacturers within China to address local market opportunities in their burgeoning markets.

Specific examples of these industrial policies include the creation of the WiBro (Wireless Broadband) standard in Korea, the adoption of domestic standards for $3 \mathrm{G}$ services (TD-SCDMA) in China, and the historical barriers erected around the European Union (EU) through various European Telecommunications Institute (ETSI) standards, which are not seamlessly interoperable with many open standards. In addition to local standards, control is also exercised through the application of protectionist policies in the allocation of radio spectrum for the benefit of local operators and equipment manufacturers. In addition to policies are the often attractive financing terms that governments extend to their domestic vendors to allow them to compete effectively and powerfully in the growing international market. Thus, companies such as Huawei Technologies Co. Ltd. (Huawei) and ZTE are capturing significant market share internationally, in large measure on the basis of their lower costs and the ability to offer attractive financing terms for their customers.

The refinements and advancements that have evolved from the combined contributions of each of these major sector development groups over the past decades have often been constrained by regulatory delays, patent and standards disputes, and the highly volatile state of the capital markets. Like so many technology-driven sectors of the economy, wireless system innovators have often faced the disruptive effects of financial market support, swinging wildly between buying frenzies and intense sell-offs. The names of the promoters and services may have changed, but the challenges and issues facing the wireless industry are clearly repeating the recurring themes from our twentieth-century history of innovation.

As we rapidly move further into the twenty-first century, our pace of development and change is accelerating, and the macro trends that will affect our industry are coming into focus. The subsequent chapters will attempt to define the key elements that will both drive us forward and slow us down as an engine of change that has proven itself capable of creating true revolutionary change throughout society in all regions of the world.

The net result of this global dispersal of wireless technology and development will exert an ever-increasing pressure on the science and innovation drivers of the industry. It is critical to note that the early work on commercializing OFDMA technology, a key technology in $4 \mathrm{G}$ wireless systems, was led by Chinese and Korean nationals. Some of these innovators had worked in the United States in early stage technology start-ups, while others were with large government research institutes and large OEM electronics-manufacturing firms. Regardless of where they were, the inventor's listed on the core patents for next generation OFDMA wireless broadband systems are predominantly Asians.

The unique contributions of brilliant individuals continue, and the authors predict that some additional names will soon be recognized among the pantheon 
of wireless technology innovators. The authors alert the readers to watch for the emergence of Dr. Hui Liu, Dr. Alex Li, Wenzhong Hong, Wei Tang, and several other innovators whose efforts have led directly to recent breakthrough developments in OFDMA technology. This team of technology developers worked together to develop and patent much of what is now the core technology being embraced by the global wireless industry for OFDMA. This core technology has been incorporated in the new Mobile WiMAX standard (IEEE 802.16[e]) and has also captured center stage for inclusion in the $4 \mathrm{G}$ standards for cellular technology. Although the WiMAX Forum and the cellular industry's 3GPP organization LTE are presently divergent in their 4G technology roadmaps, they both embrace OFDMA as the core wireless technology for the next generation of mobile wireless systems. The merits of OFDMA technology are discussed in detail in Chapter 10.

Recently, a number of early stage firms have found both investment and market traction in emerging markets, including India, China, and Eastern Europe. This development is in sharp contrast to similar early stage ventures in the United States, which have been struggling through the challenges left over from the recent depression in the sector and whose ranks have largely been diminished through their sale or merger with larger, more established concerns. The returns that they delivered to their investors were far below the range that $\mathrm{VC}$ investors require to sustain continued interest with investment in the sector. Much excitement was seen at the time of the Qualcomm acquisition of Flarion for about $\$ 600$ million, but in reality, this represented only about a $3 \times$ return on the invested capital over almost eight years. Recently the acquisition of Navini by Cisco generated a purchase price that returned only about $2 \times$ to the venture investors over nine years. Earlier, IPWireless was sold to Nextwave for a price that was substantially less than the invested capital. The failure to deliver financial returns that create enthusiasm among the $\mathrm{VC}$ investment community will negatively affect the next wave of wireless innovators in the United States. When market conditions and risk capital are readily available to innovators in emerging nations, it will result in a continued shift of technology development and new venture formation to more friendly locations. The migration from long-term patient investment in core technologies to shorter-term, higher-return investments will lead the U.S. VC industry to squander its attention and capital in the current bubble market for Web 2.0 Social Networking ventures. The resulting scarcity of risk capital in the United States to fund new wireless technology ventures will contribute indirectly to the continuing international diaspora of wireless broadband talent and opportunities.

The message is simple: The United States is at immediate peril of slipping from its position of global technical leadership in the wireless broadband industry into a role of just being a "trading nation," relying on profits of being a financial intermediary rather than being a true value creator among the leading technology development and applied technology commercialization nations. There is an urgent need in the United States for a comprehensive industrial development policy, tied closely with increased attention paid to our growing technical education gaps with competing nations worldwide. 


\section{CELLULAR CARRIERS: STUCK ON STICKINESS}

Our almost universal adoption of mobile phone services has conditioned our society to expect certain things about their service and to accept (through lack of any substantive competition to date) an arbitrary set of rules that define our commercial relationship with our service providers. Legacy cellular operators have created numerous marketing programs, with policies designed to maintain the customer relationship (the "stickiness" factor). Long-term contracts tied to free or discounted phones are the norm. The introduction of number portability a few years ago broadly exposed the "fine print" requirement for customers required to buy out the full-term value of their cellular contracts before being able to port their cellular number to another carrier. This industry-wide sales policy has created pretty extreme stickiness, by almost any measure. The impact on wireless customers has been significant, and given the high degree of vertical integration that has resulted from the consolidation of the leading wireless service providers back into the largest wireline telephone companies, it will be extremely unlikely that these market leaders will lead with innovation.

Verizon and AT\&T now dominate the industry post their reconsolidation, and these firms have demonstrated the most onerous business practices in the quest to keep customers captive to their services. Locking phones and imposing network control to keep phones not obtained from the carrier off the network are their standard business practices. Further, their data services have contractual limitations on the use of bandwidth that rigidly constrain subscriber use of their Internet access services. Although these data contracts have apparently been crafted to prevent abuse by subscribers using their IP connections for applications that far exceed what the carriers have determined are "normal usage limits," they also prohibit the use of these systems to access solutions that may compete with their core voice and walled garden data applications, such as VoIP services that use software applications like Skype, Gizmo, or other "soft phone" clients, which could easily be integrated into cellular handsets. Franchise protection and customer retention have become a high priority among U.S. and many international cellular operators, with a wide range of defensive strategies being tested or implemented, including adding packet time delay (degrades VoIP service quality) and network sniffing of unauthorized applications. Protectionism is growing in proportion to the increase in the power and availability of Internet-centric, open source data services, spoofing rigidly controlled legacy-closed service bundles.

\section{"Unsticking" the Carrier Relationships}

As we move toward the inevitability of open wireless broadband network availability, the marketing crossroads will be where the Internet culture of open access and open systems collide with the traditional telephone system-inspired closed architecture of the cellular operators. The authors predict that there will be a wide range of new business models trialed by new service providers, ranging from traditional subscription services to permutations of prepaid, 
pay-per-consumption, metered services with postpaid billing, and at the other end of the marketing spectrum, free, advertising-supported wireless broadband services can also be expected to emerge from some service providers.

The next wave of wireless competition has already begun on the heels of the Clearwire Mobile WIMAX deployments. Clearwire has claimed that they will pioneer open access to their broadband IP network to allow any Mobile WiMAXcertified compatible user devices conforming to the 802.16(e) standard. If their large-scale network deployments make it through the current financial challenges facing the consortium of pioneering firms, it will be the first mass-market assault on the traditional, closed approach institutionalized by the existing cellular operators that leverages crippled user terminals that are only usable on a specific network. The bifurcation of the mobile wireless industry into opposing camps with extremely different network assets and infrastructure will define the early battle lines over who will be the winners and losers among the new broadband wireless service providers.

In addition to expanding competition from Mobile WiMAX and metropolitan area-wide WiFi initiatives, there will soon be other new competitors emerging from the 700-MHz auctions and from among other large-scale spectrum holders such as Nextwave. Although the authors believe it will take the better part of the coming decade to allow sufficient time to enable the widespread ubiquity of wireless mobile broadband to be achieved, it will only take a few years to allow these new competitors to exert their influence on the market. For the first time, legacy cellular operators will face unprecedented competition that will be differentiated not just on price, but on a variety of enhanced services as well, which we anticipate will lead to their bringing LTE service upgrades to market sooner than if there was no new competition. The migration of the voice-centric cellular networks to broadband data services will inevitably be accelerated when carriers are faced with substantive market competition from new IP data-centric wireless operators. It is important to note that the legacy cellular operators have been struggling to keep up with the demand for increased data services and a burgeoning industry-wide belief in the extension of broadcast and on-demand video services into the personal mobility market.

Neither the existing GSM nor CDMA networks are particularly well suited to deliver broadband IP services to their subscribers. The U.S.-based GSM carriers T-Mobile and AT\&T (including Cingular) have been slow to widely deploy WCDMA in the United States, which will require 5-MHZ-wide channels to implement. To date the GSM carriers have relied heavily on GPRS* and $\mathrm{EDGE}^{\dagger}$ to deliver most of their data services, which co-exist within the standard voice channel framework of $200-\mathrm{kHz}$-wide radio frequency channels with eight TDMA (time division multiple access) time slots. The economics of GPRS are

\footnotetext{
* GPRS - General Packet Radio Services. GPRS is a packet-based wireless protocol for integration with $2.5 \mathrm{G}$ GSM networks featuring data rates from 56 up to $114 \mathrm{Kbps}$.

${ }^{\dagger}$ EDGE - Enhanced Data GSM Environment. EDGE is a faster version of GPRS wireless data service. It enables data to be delivered at rates of up to $384 \mathrm{Kbps}$.
} 
extremely painful to the voice revenue capacity and network efficiency for GSM operators. GPRS typically bonds four (of the 8 available) TDMA voice quality time slots to deliver what is in reality only performance at the low-end of wideband speed data service. T-Mobile has responded aggressively to this challenge by pioneering WiFi hot spot access to augment its cellular data services, and recently to pioneer Unlicensed Mobile Access (UMA) services with the addition of dual mode GSM/WiFi phones and home installation of T-Mobile hot spots.

U.S.-based CDMA carriers, dominated by Verizon and Sprint Nextel, have fared marginally better with their delivery of data services using evolution-data optimized (EV-DO) network enhancements and wider deployments of CDMA2000 3G infrastructure in numerous markets. These data-centric network elements in heavily loaded networks are still only capable of delivering wideband services to large numbers of simultaneous users, which is substantially less than one megabit per second. However, it should be noted that the implementation of data services is consistently managed on discrete channels that are not shared with voice services. Indeed the incorporation of 3G into the CDMA2000 network operators has in large measure been consumed by increased voice traffic, rather than portioned to support significant data services.

As mobile wireless systems continually strive to keep abreast of the burgeoning customer demand for both basic and enhanced data services and high speed Internet access, the need to be as spectrally efficient as possible will emerge as a key determinant of network technology selection, as the subscriber base has now grown to over 200 million in the United States. As we look back at the digital evolution of the cellular industry, we can observe this trend in retrospect. The original cellular networks were based on FM analog radio technology, and required a discrete $30-\mathrm{kHz}$ radio frequency (RF) channel to support each voice conversation. As we moved forward with the original migration to digital technology TDMA techniques were adopted (see IS-54), supporting four simultaneous voice conversations within each $30-\mathrm{kHz}$ RF channel-a fourfold increase in efficiency over the analog systems. In parallel, the EU also adopted TDMA technology as the core for the GSM standard, which was enabled using 200-kHz RF channels with eight time slots for carrying traffic. Subsequently, Qualcomm began advocating CDMA as a more spectrally efficient means of delivering voice services and drove through the second U.S. cellular standard (IS-95). The CDMA implementation used $1.25-\mathrm{MHz}$ wide RF channels that typically support 64 simultaneous voice conversations. In practice, the CDMA solutions are between four and eight times more spectrally efficient than the TDMA systems. The growing scarcity of radio spectrum in the frequencies that are practical for mobile non-line-of-sight services makes spectral efficiency a central issue for any new mobile system architectures to consider. This requirement is now driving all wireless network planners to seek the next level of spectral efficiency that has been demonstrated by OFDMA technology, and incorporated in the 802.16(e) standard for what is now being commercialized as Mobile WiMAX. 
Both the cellular industry's 3GPP technology organization and the WiMAX Forum have selected OFDMA as the technology of first choice for the 4G mobile wireless networks. Thus, we see a collision of standards derived from different roots, but with similar goals and objectives for network efficiency and performance.

The mobile wireless industry is following a bifurcated trail that leads to the implementation of $4 \mathrm{G}$ platforms. The existing cellular industry is evolving its $2 \mathrm{G}$ "narrowband" GSM and CDMA networks along the 3GPP roadmap through the 3G "wideband" era into the LTE technology, which will ultimately incorporate an OFDMA-based solution. In parallel, the emerging Mobile WiMAX carriers are already deploying OFDMA-based networks following the 802.16(e) Mobile WiMAX standard. The power of the legacy cellular operators to maintain their market dominance will thus be severely challenged as new service providers enter the market with solutions that are already as powerful and flexible as the LTE 4G vision, which is not anticipated to enter the global wireless infrastructure market until 2010. As with all things in the domain of technology in the early twenty-first century, we find the speed of change accelerating with little consideration during this change to the financial exposures of last-generation platform-based businesses. In addition, as we enter into the "long tail"* Internet economy, with mass specialization, featuring a steady decrease in horizontal homogeneous markets in favor of a very large number of specialized niche markets, the need for legacy service providers to reinvent their business models will be an essential requirement for survival. The question for investors, regulators, vendors and consumers is a big one: Can they do it? If not, how they milk their installed base and capture capital for returns in a declining market that will provide the material for a future generation of Harvard Business School case studies. Balancing survival in the midst of rapid obsolescence and technology evolution will take tremendous creativity, commitment, and investors with an awareness of the long-term benefits of supporting the wireless industry from peak-to-peak of successive waves of progress, but on a timescale that must be measured by half-decade cycles, not recurring quarterly performance panic attacks.

The business models for the legacy cellular operators, which have largely been closed proprietary environments, are also going to face competition from a number of new access models ranging from free, advertising-supported services, to pay-per-consumption metered services, and even various permutations of traditional subscription services. The U.S. GSM operators have typically constrained handsets to those purchased directly from the carrier by locking the SIM card instruction sets to limit the use of the phone to only their network - a limitation, by the way, that can be overcome by just about any independent cellular retail outlet in GSM-served nations for about \$20. Similarly, the CDMA network operators have constrained independently supplied phones by blocking non-preregistered electronic serial numbers (ESN) in their switching systems.

\footnotetext{
* Anderson authored a book on the subject, The Long Tail: Why the Future of Business is Selling Less of More (2006).-Citation and Figure 3-7 from Wikipedia.
} 
Regardless of how future users of converged broadband services obtain their connectivity, the applications that evolve to deliver the greatest personal value and utility to users of all types, ranging from personal services to commercial and government applications, will undoubtedly benefit from the availability of broadband connectivity into all application domains. Spectrally efficient broadband wireless systems will not only increase the number of simultaneous voice conversations a given amount of bandwidth can deliver, it will also allow for enhancements in voice quality and applications. Broadband wireless will also allow for the true convergence of voice, data and video, enabling all services to be available at any location from which the user may seek access.

\section{MANAGED NETWORK SERVICES: THE OUTSOURCED NETWORK}

We should not get too far afield while contemplating the cellular business of the future without examining some of the new business models that are emerging in the industry. Among the most innovative and substantive changes to the core business model of successful wireless carriers is the concept of outsourcing the entire access and transport network to third parties. The utilization of all or partial outsourcing of the network essentially transforms the core business into a pure marketing and sales organization, with a fixed cost associated with network operations for the first time. In what circumstances does this fairly radical approach make sense, and at what level of critical mass can or should it be justified? The business decisions attendant to this board room and management decision is nontrivial, and the potential for disaster is significant. However, if successful, the approach appears to deliver a very powerful transformative influence on the early pioneering operators using the outsourced network approach.

The concept for network outsourcing follows the trend in many industries to seek ways to hand off processes and business elements to specialist third parties whose concentration and scale allow them to accomplish the required mission at a lower cost, with higher efficiency, and with better quality. Responsiveness to outages and network management are efficiently removed from being a variable cost to a contractually defined set of requirements at a predetermined fixed price. If these efficiencies are indeed integrated into the outsource network services contract, then the underlying cellular service provider can concentrate management and financial resources on improving their marketing and sales efforts. Maintaining quality of service and formulas for adding capacity and new features and service platforms to the network must be carefully anticipated, and the agreements must be flexible enough to allow both parties to adapt to rapidly changing market requirements in a win-win environment. Alternatively, as soon as the balance tips into asymmetric suffering or squeezed margins, the outsource relationship will start to unravel quickly.

Typically managed network services are provided by the major infrastructure equipment manufacturers who are seeking to improve their participation in the 
value chain by moving deeper into services. Their unique capabilities to engineer, project manage, design, install and maintain network facilities empower these organizations to capture a position of leadership in the field. The other potential groups of organizations who are well positioned to participate in this new model are the major systems integrators (SI).

Early wireless infrastructure vendors pioneering this new model include Ericsson, with complete network responsibility for the company 3 Networks in the United Kingdom and over 30 carrier clients worldwide, and Nokia Siemens Networks, which has contracted managed services with 34 clients in 28 countries, providing managed network services for over 20 operators internationally.

One of the most comprehensive and successful users of outsourced network operations is, Bharti Airtel Limited (Bharti) in India. Bharti has contracted with a number of outsource specialists for various elements of its business operations, including IBM for IT support, Nortel for call center services, Ericsson for the management of more than $70 \%$ of its GSM network infrastructure, and Nokia Siemens Networks for the expansion of rural cellular and fixed lines. As Bharti expands into international markets, it is also using managed network services to efficiently enter new markets. For example, in Sri Lanka, its local subsidiary Bharti Airtel Lanka Private Limited, has a managed network services relationship with Huawei, for the construction and operation of a $2 \mathrm{G}$ and a $3 \mathrm{G}$ network.

A recent In-Stat [4] report has estimated the market for managed network services. The following is a summary of its key findings:

- The total mobile managed services market is expected to double over the next five years; growing from \$22.2 billion in 2006 to $\$ 52.2$ billion in 2010 .

- The evolution of network operator infrastructure technology is creating opportunities for vendors to provide managed services to mobile service providers.

- Markets for traditional managed services, such as customer care and billing and network management, will continue to grow, but will be eclipsed by rapidly growing markets for managed network services running the entire access and transport network.

- Virtually all leading mobile infrastructure and applications vendors are developing and marketing comprehensive managed services solutions for carriers as they evolve their business models to embrace outsourced solutions.

\section{ENHANCED BROADBAND VOICE}

Even mundane voice services will be favorably impacted by the advent of broadband wireless as the value of improved audio quality is added to the delivery of traditional voice services, thus enabling a wide range of innovative new categories of voice and audio communications. High fidelity voice, stereo voice, 
voice storage, audio blogs, enhanced voice mail, voice integrated into gaming, and audio text services will all benefit from the incorporation of broadband connectivity into the realm of voice communications. In addition to the increased bandwidth, the evolution of voice services have also been affected by the migration to VoIP, which has simplified the management of voice distribution to include one-to-many conference calling, group calls established on demand, push-to-talk features, and incorporating virtually any number of simultaneous participants as desired. Further, when voice is translated into an IP-compatible format, the archiving of conversations for later retrieval, and the seamless integration of voice into unified messaging systems will spawn further new applications and services that have voice as a key element.

The emerging broadband access capabilities will also have disruptive impacts in the domain of LD voice services. The cellular industry pioneered the "postalization" of domestic LD services when it combined airtime and LD services into a fused flat rate per minute. Previously, LD services were sold on a distancesensitive basis, and the new concept treated LD the same as the postal service treated first-class mail, one price to any U.S. location. AT\&T Cellular pioneered this market-changing breakthrough under Dan Hesse's leadership, with its innovation of "bucket" plans for monthly pools of airtime, which were billed on a flat rate for various amounts of service, including LD charges. Additional airtime is charged at much higher rates, incentivizing customers to purchase the largest size bucket plan per month that matches their typical usage profiles. This take or pay approach revolutionized the cash flow metrics of the cellular industry and has become the norm for virtually all U.S. cellular operators. Now the forces of the Internet are coming to bear upon both the cellular industry approach to bundled airtime and LD services by converting voice to a simple data application.

Similarly, the integration of speech recognition technologies is already making inroads into the VoIP market with new services and applications for the conversion of speech to text and text to speech. These additions to the applications developers' tool kits will inevitably impact the future of messaging systems and cross-platform digital voice.

The negative impact of VoIP on the economics of traditional cellular business voice models is potentially devastating. Presently, voice still accounts for cellular revenues in excess of $85 \%$. The bundling of air time and LD services created a new paradigm for charging for voice services, but with the resulting fees still averaging $\$ 0.10$ per minute within the presubscribed "bucket plan allocations," and $\$ 0.25$ per minute if the users consume airtime beyond their subscription limits, the cellular industry remains a hugely profitable enterprise. Recently there has been a new marketing approach to bring "all you can eat" plans to the market by the cellular service providers. It is too soon to tell what long-term impact these plans will have on the industry. They are a bargain for the power users, and perhaps a means of increasing the ARPU for less voluminous users. These existing retail price plans are on a collision course with the rapidly maturing and improving Internet-based voice service delivery models such as Skype or Gizmo, wherein peer-to-peer connections are essentially free. As broadband wireless IP services 
become widely available, how service providers manage the competitive challenge of these alternative bypass technologies using their access networks to compete against the carriers own voice services will become the fulcrum on which the future of the industry is determined.

As voice is converted to an integrated data application element within generic IP data streams, it becomes increasingly clear that maintaining the present level of revenue from traditional voice services is highly unlikely. How the legacy cellular operators will adapt to the new realities will be a major determinant of how the wireless industry evolves to embrace the new technologies of broadband wireless, or how they will simply devolve into lesser lights of the future wireless broadband landscape. There are many parallel issues between the present market dominance and financial power of these legacy operators and their landline telephone company parents. Large top line expenses, driving business through regulatory protectionism, and supporting profitable mass market generic revenue streams, which are unlikely to be sustainable into a future populated by computing-centric broadband wireless networks. Will the legacy operators engage in the fight to maintain their market dominance through direct engagement with the new IPcentric wireless operators, or will they seek to mount a rearguard defensive posture reminiscent of that brought to bear against the CLECs and DSL service providers by the ILECs? Given that the ILECs are now the largest cellular operators, the question is whether the tiger can indeed change its stripes. Because of the self-sufficient capabilities of end-to-end autonomous networks that are anticipated in the Mobile WiMAX market, the expected collision will be one of the best wireless developments yet for consumers and for all related businesses that constitute the wireless broadband ecosystem worldwide to test these issues.

\section{FIXED MOBILE CONVERGENCE}

There are presently a number of fixed mobile convergence initiatives under way. Although one would expect that the wireline cellular operators would lead in this space, it is interesting to note the progress being made by T-Mobile with the introduction of a UMA GSM/WiFi-enabled phone package that leverages a combination of "bring your own broadband" (FTTX, cable modem, DSL, or wireless broadband) connections for installation of a home WiFi hot spot that allows subscribers to use their T-Mobile phones in a VoIP no-airtime-charge (fixed monthly fee) modality when within range of their home's or any T-Mobile hot spot. The willingness of telco-owned cellular operators to cannibalize their own revenue streams to provide competitive and innovative new services will be a large determinate of identifying the future survivors in the emerging, hypercompetitive wireless broadband marketplace. Careful and incremental management of evolutionary change is the proven specialty of large-scale telecommunications operators. The test of how well these skills will serve their pending battles with new types and kinds of competitors overlapping their legacy franchises will begin in earnest by the end of 2008. It may take five more years for the competitive 
landscape to mature to the point of truly competitive market engagement, but with the drive by the computing and broadcast industries into the domain of wireless personal communications, the clash of innovation versus protection of the established businesses is inevitable.

\section{Fixed Mobile Convergence in the Enterprise}

There is another emerging market that is leveraging the potential for fixed mobile convergence. Large business down to and including SMEs are being addressed by a growing number of new types of mobile virtual network operators (MVNO) whose mission is to capture the largely under-managed and out-of-control commercial cellular use by employees using cell phones in their business. The concept leverages on-site microcells that capture traffic from standard mobile handsets coordinated under the company's unified management control, typically outsourced to the system integrator or enterprise-focused MVNO service provider. Thus when employees are at work or in corporate-owned facilities, all their cellular traffic is carried via the company's internal virtual private network (VPN), and when the employees are out in the field, they are simply "roaming" onto the MVNO-underlying nationwide network, but all billing and customer support is managed by the company or its enterprise MVNO. Further enhancements to this model include the addition of PBX desk set and VoIP-based features and capabilities into the cellular handset when it is on the enterprise intranet.

Pioneers in this space include companies such as Strata8 Networks, Inc. and Sotto Wireless, Inc., both coincidentally located in Bellevue, Washington, and Spring Mobil headquartered in Stockholm, Sweden.

We anticipate that the market for managed network services and outsourced VoIP PBX services for the enterprise will evolve to become fully complementary in addressing the market requirements for fully converged services, including the mobile extension to the desktop.

\section{BOUNDARY BLURRING}

The wireline, cellular, cable television, direct broadcast satellite (DBS) television, Internet service providers, radio and television broadcasters, and content owners are all in a mad race to invade and capture enduring relationships with each other's customers. How content is made available to customers is heading for a "jump ball" environment between and among these historically dominant players in each of their respective domains. How the concept of "subscriber" evolves to address an environment of unprecedented consumer choice, wherein "customers" make content and service decisions on the basis of a comparison of all aspects of price, performance, convenience, service quality, and ease of use, will be determined in the new, complex market into which the wireless broadband industry is rapidly morphing. Responding to this changing environment is the massive opportunity facing our industry. New fortunes will be made, and others 
diminished, as the winners are identified among all the participants on the value chain.

The concept of convergence is finally, after a decade-and-a-half of promising talk becoming reality. Further, the concept has evolved enough to go well beyond the idea of voice, data, and video convergence to also include all aspects of mobility, leveraging the networks serving the home, the office, and mobile, delivering on-demand content to every type of platform. The ability for content providers to simultaneously deliver their products to all three screens for image and video content, including the television, the desk top or laptop computer screen, and the small-scale screen of handheld mobile devices constitutes the new fully converged quadruple-play environment.

\section{REFERENCES}

1. Juniper Research. Mobile Broadband Markets, WiMAX, EV-DO, HSPA \& Beyond, 2007-2012. Hampshire (UK): Juniper Research; Aug. 2007.

2. Charles Lindblom. The science of muddling through. Public Admin Rev 1959; 19: 79-88.

3. United States District Court for the District of Columbia, Civil Action No. 82-0192, filed August 4, 1982. Modification of Final Judgment with American Telephone and Telegraph.

4. In-Stat Report. Managed Network Services for Mobile Operators. In-Stat; Copyright (C) 2007. 
